COMECHINGONIA. REVISTA DE ARQUEOLOGÍA

Número 15, 2011, pp. 17-37, Córdoba

ISSN 0326-7911

\title{
MODALIDADES ESPACIALES Y FORMAS RITUALES. LOS PAISAJES RUPESTRES DE EL ALTO-ANCASTI.
}

\author{
Marcos N. Quesada ${ }^{1}$ y Lucas Gheco ${ }^{2}$ \\ ${ }^{1}$ CONICET - Escuela de Arqueología, Universidad Nacional de Catamarca. \\ mkesada@yahoo.com.ar \\ ${ }^{2}$ Escuela de Arqueología, Universidad Nacional de Catamarca. \\ gheco@hotmail.com
}

Presentado el: 08/08/2011 - Aceptado 20/10/2011

\section{Resumen}

En este trabajo buscamos definir distintas lógicas espaciales en la construcción social de los entornos rupestres de las Sierras de El Alto-Ancasti. Para ello realizamos un análisis comparativo de diez sitios arqueológicos. Nuestra metodología considera la idea que una de las dimensiones fundamentales del arte rupestre es la visualidad y que ello define la estructuración del espacio en torno a él. Definimos cuatro modalidades espaciales considerando las posibilidades de visualización, agregación de personas y movimientos corporales que los entornos rupestres promueven o limitan, entre otros elementos de análisis. Interpretamos dos de estas modalidades como estructuras espaciales de formas rituales particulares y exploramos los límites y alcances de la definición de estas lógicas espaciales en términos de la tensión entre lo general y lo particular en el arte rupestre a distintas escalas de análisis.

Palabras claves: Arte rupestre, Sierra de El Alto-Ancasti, modalidades espaciales, formas rituales.

\begin{abstract}
In this paper we define different spatial logics in the social construction of the rupestrian environments of the Hillands of El Alto-Ancasti. To do this we conducted a comparative analysis of ten archaeological sites. Our methodology considers the idea that one of the fundamental dimensions of rock art is the visual and that this defines the spatial estructure around it. We define four types of spacial modalities considering the possibilities of visibility, aggregation of people and body movements that allow the cave environments, among other elements of analysis. We interpret two of these modalities as scenes of ritual forms and explore the individual limits and scope of the definition of these spacial logics in terms of the tension between the general and the particular rock art at different scales of analysis.
\end{abstract}

Keywords: Rock art, Hillands of El Alto-Ancasti, spacial modalities, ritual forms.

\section{Introducción}

La Tunita, La Candelaria, Oyola, Campo de las Piedras son sólo algunos de los sitios de la Sierra de El Alto-Ancasti (Prov. de Catamarca) en los cuales el arte rupestre alcanzó un 
notable desarrollo. Tal situación ha llamado la atención de los investigadores desde hace ya unas décadas al punto que en la actualidad es prácticamente el único aspecto que conocemos sobre el pasado prehispánico de esta zona. Como sucede generalmente en el estudio del arte rupestre, también aquí fue considerado principalmente como soporte visual de mitos orales o expresión pasiva de religiones, culturas o períodos (por ejemplo: González 1977, 1998; Gramajo y Martínez Moreno 1982; Gudemos 2003; Segura 1970, entre otros), descuidando quizá el hecho que el arte rupestre es un fenómeno real y con capacidad de crear realidad, como intentaremos sostener en esta oportunidad posicionándonos desde una arqueología de la práctica.

Nuestra estrategia metodológica considera la capacidad del arte rupestre para estructurar la práctica en torno a él (Troncoso 2007, 2008). Proponemos que tal metodología puede resultar de valor a la hora de interpretar la manera en que éste participaba en la práctica ritual que tomaba lugar en estos particulares sitios de las serranías de El Alto-Ancasti porque permite posicionar a los sujetos en relación al arte rupestre. Centrándonos en la disposición de los motivos y su vinculación con el entorno, y dejando por un momento de lado el análisis iconográfico e iconológico, intentaremos mostrar la manera en que el arte rupestre participó en la conformación de espacios constitutivos de los procesos rituales.

\section{Los espacios rupestres de El Alto-Ancasti}

La Sierra de El Alto-Ancasti flanquea por el Este la ciudad de San Fernando del Valle de Catamarca, constituyendo la última estribación serrana para dar paso, al oriente, a la llanura santiagueña. Típica representante de las Sierras Pampeanas, su ladera occidental se erige abrupta, al ascender varios cientos de metros en escasa distancia. En contraposición, la cara oriental desciende por más de cuarenta kilómetros, recorrido a través del cual se deja atrás el pastizal de altura para atravesar una franja de bosque serrano $y$, finalmente, introducirse en un tupido monte xerófilo. En las lomadas de la vertiente oriental de El Alto-Ancasti, se encuentran numerosas cuevas, abrigos y bloques rocosos en donde los antiguos habitantes de la zona plasmaron gran cantidad de pictografías y petroglifos. Para este trabajo serán de importancia los siguientes sitios: Oyola y Casa Pintada de Guayamba en el Dpto. El Alto; La Tunita, Campo de las Piedras, La Candelaria II, La Piedra con Pinturas de El Taco, Rastro del Avestruz y Puesto La Mesada en el Dpto. Ancasti y El Tipán en el Dpto. Capayán (Figura 1). Algunos de estos sitios han sido mencionados por otros autores y caracterizados con mayor o menor detalle. Aquí nos valdremos de algunos aspectos de esas descripciones, que serán completadas mediante nuestras propias observaciones. La Piedra con Pinturas de El Taco y Rastro del Avestruz son presentados por primera vez en este trabajo.

Quizá por lo destacado del estilo figurativo de los sitios más conocidos, la investigación del arte rupestre de esta región se orientó principalmente hacia aspectos iconográficos e iconológicos. En esta oportunidad dejaremos de lado estos enfoques, o les daremos un lugar secundario en el análisis, y en cambio intentaremos ensayar sobre la manera en que la disposición espacial del arte rupestre organizó las prácticas en torno a él. Esto supone la caracterización de los contextos donde era representado y las condiciones y posibilidades que estos escenarios establecían a la visualización y desplazamiento. Para esto nos valdremos de un principio metodológico ya anunciado que supone que antes que cualquier objetivo que el arte rupestre tenga en el contexto que fuera, el primer fin que esta peculiar materialidad tuvo es el de ser visto ya que es la visualidad, término que empleamos aquí en sentido amplio para indicar que se trata de una forma cultural que se experimenta y transmite a través del 


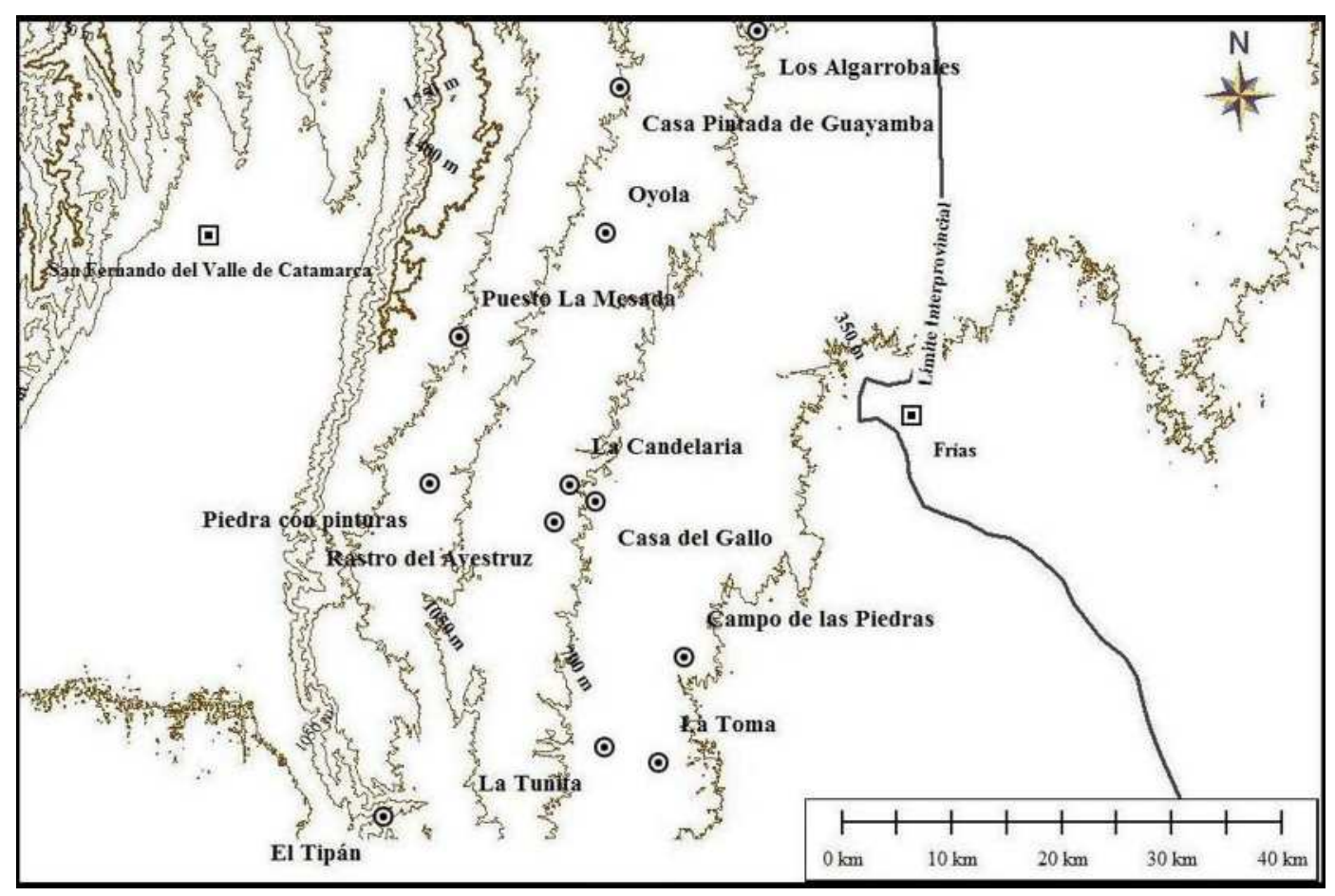

Figura 1: Ubicación de los sitios con arte rupestre de las sierras de El Alto- Ancasti considerados en este trabajo.

sentido de la vista, su principal característica. Es decir, sea cual sea la función a la cual estaba destinado: marcador territorial, soporte visual de mitos, representaciones de deidades, etc., la condición para la realización de ese objetivo es que sea visto. Pero más importante aún es que tiene la capacidad de definir de que maneras debe ser mirado y de que maneras no. En cada contexto particular, el arte rupestre prescribe y proscribe de manera distinta las líneas visuales, los movimientos corporales y las posibilidades de agrupamiento de los actores que participan de las prácticas que toman lugar en esos entornos. El arte rupestre tiene la capacidad de estructurar la práctica en torno a él creando diferente condiciones de visibilidad, es decir, formas culturales de "administrar" la visualidad.

Vamos a intentar mostrar que en las serranías de El Alto-Ancasti estas condiciones de visibilidad o, vistas desde otro lado, formas de exhibición, se organizan en, al menos, cuatro lógicas o modalidades espaciales diferentes. Para ello tendremos en cuenta: a) la disposición de los sitios en el paisaje, b) las condiciones de visualización de los bloques o cuevas donde se hallan los motivos, c) las condiciones de visualización del paisaje desde los sitios, d) la visualización de las figuras desde el exterior o interior de los bloques o cuevas, e) el acondicionamiento material del espacio en torno a las representaciones rupestres.

Vamos a advertir antes de avanzar, que las consideraciones sobre estos aspectos no necesariamente se pueden expresar cuantitativamente por dos motivos. Por un lado, porque, como ya indicamos, algunos de las observaciones proceden de textos de otros autores quienes han consignado sus datos de maneras diferentes y no siempre cuantitativas. Por otro lado, porque algunos de los elementos que consideramos para la definición de las 
modalidades no pueden ser expresados por un rango de valores o un límite determinado ya que frecuentemente refieren a cualidades que deben ser descritas antes que a cantidades que puedan ser medidas.

\section{Modalidad 1: La Tunita, Oyola y Campo de las Piedras}

Los sitios que corresponden a esta modalidad tienen la particularidad de ubicarse en lugares relativamente elevados en relación a los arroyos y ríos. En los tres casos, Oyola (Figura 2), Campo de las Piedras y La Tunita, los sitios se disponen sobre afloramientos graníticos (Battaglia 1982) que se caracterizan por la existencia en sus cimas y laderas de un gran número de cuevas y abrigos labrados por la erosión en la base de grandes bloques (Figura 3 y 4 ).

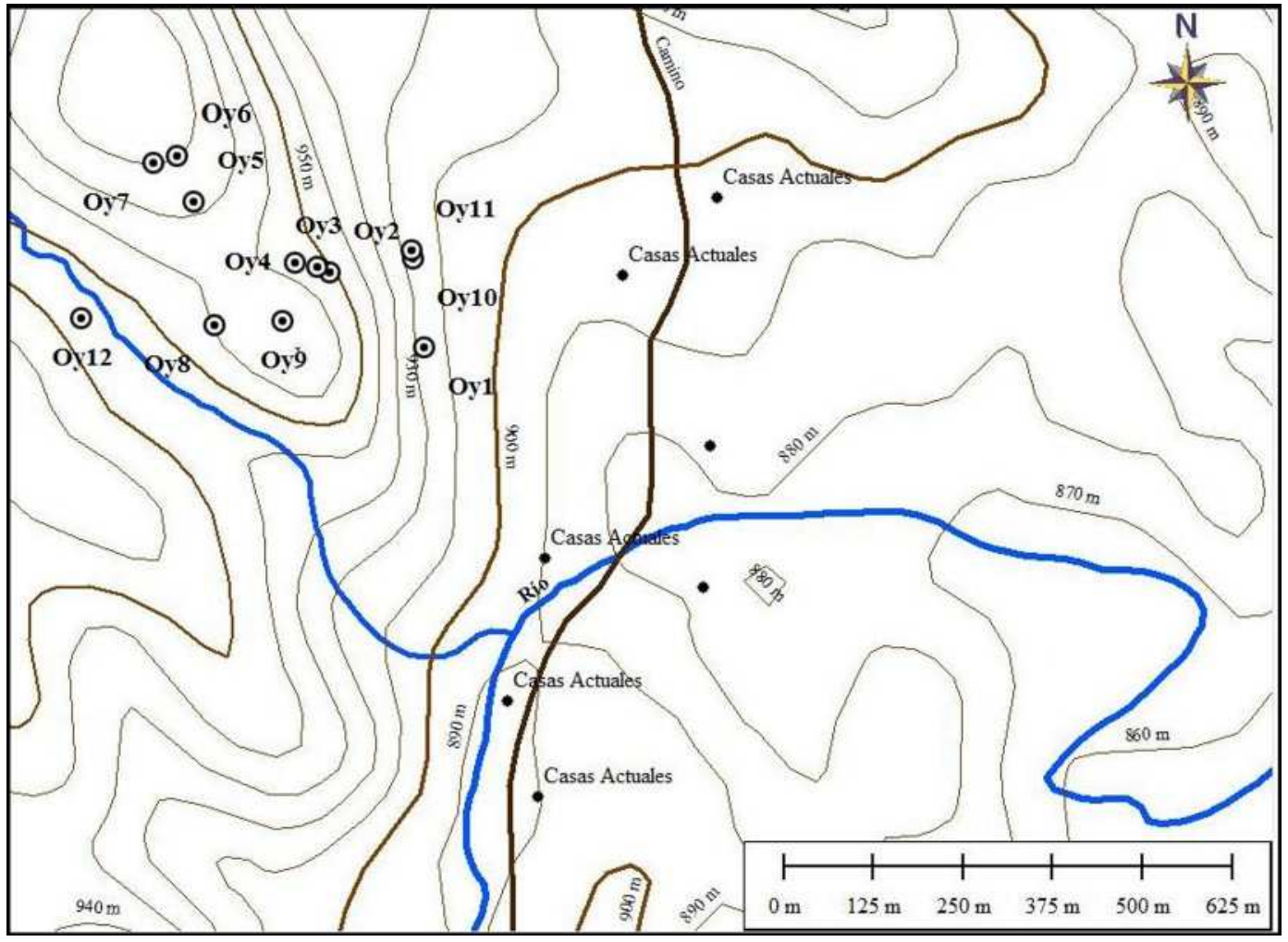

Figura 2. Distribución de las cuevas con pinturas en el sitio de Oyola

La ubicación en sectores elevados y, sobre todo, la tupida vegetación del bosque de cebil y otras especies arbóreas de gran porte que rodean las cuevas ${ }^{1}$, provocan que esos enormes bloques pétreos no sean en general visibles si no es desde algún privilegiado punto elevado o hasta que uno se halla muy cerca de ellos, cuando emergen del espeso monte de manera sorpresiva causando una fuerte sensación de contraste con el entorno vegetal.

Del mismo modo que la vegetación dificulta fuertemente la visualización de los sitios desde la distancia, también dificulta la visual desde los sitios. En general puede uno ver el entorno inmediato, visual que es rápidamente bloqueada por el follaje, o a una gran distancia, pero no a los sectores bajos adyacentes donde parecen haber estado los sitios de habitación y de cultivo contemporáneos (Gramajo y Martínez Moreno 1982). 
También es común a estos tres sitios el hecho que en cada caso fueron varias las cuevas elegidas para plasmar los motivos rupestres. La distancia máxima entre cuevas vecinas no excede los $700 \mathrm{~m}$ aunque frecuentemente están muy próximas, como el caso de las llamadas La Sixtina y El Hornero en La Tunita, distantes unos $20 \mathrm{~m}$ una de otra. De acuerdo con Gramajo y Martínez Moreno (1982) en Oyola son 7 los abrigos rocosos con pinturas, aunque nuestras investigaciones señalan que no son menos de 17. En Campo de las Piedras, Segura (1970) describe 3 cuevas a las que se suman otras dos detectadas por nosotros en nuestra visita al lugar². Para el caso de La Tunita, tanto De la Fuente (De la Fuente y Díaz Romero 1979) como Nazar (2003a) coinciden en indicar que se trata de varias cuevas pintadas, sin dar mayores precisiones. Nuestras observaciones indican que la cifra no es inferior a 10.

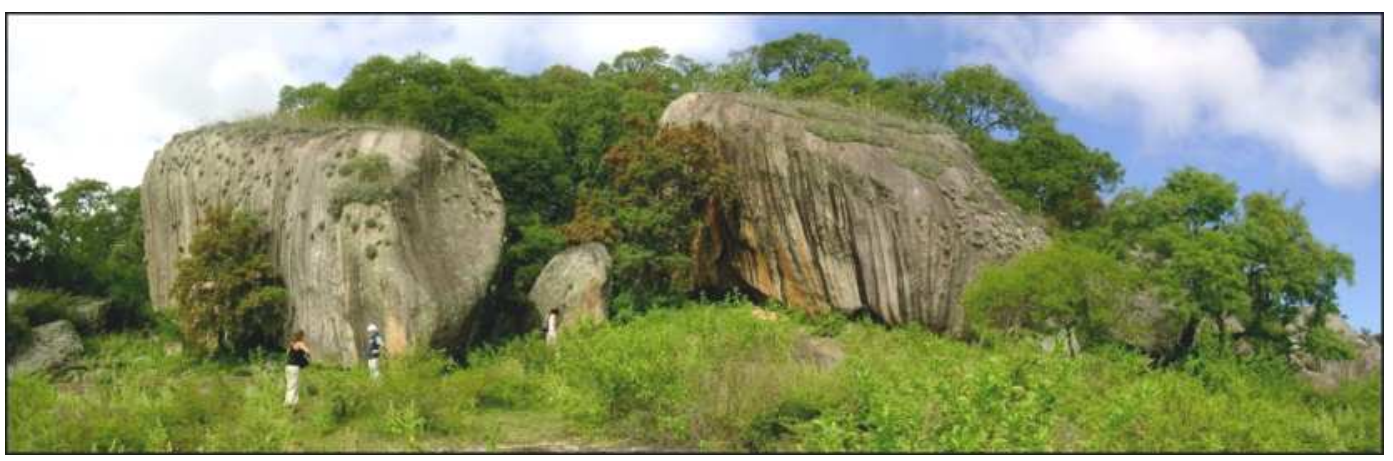

Figura 3. Bloques de granito bajo los cuáles se encuentran las Cuevas 2 y 3 de Oyola

No todas las cuevas fueron pintadas. Al parecer hubo algún criterio de selección de los lugares que podían serlo. Parece un hecho común a los tres casos que estamos caracterizando la preferencia por ubicar los diseños en espacios que tienden a limitar la congregación de personas. En Oyola, las cuevas de mayores dimensiones no fueron pintadas, aún cuando el soporte rocoso era idéntico a las que si lo fueron. En cambio, se eligieron con ese fin pequeñas oquedades adyacentes a las cuevas grandes o directamente otras cuevas mucho más pequeñas (Figura 5). En general las figuras no son visibles desde fuera de las cuevas. Son excepciones a lo dicho las pequeñas Cuevas 8 y 10 que, si bien los motivos que albergan pueden ser vistos desde afuera, este mismo espacio exterior está muy limitado por otras rocas y la abrupta ladera de la montaña. En La Tunita parece haber una lógica similar. Nazar, quien investigó allí, indica que:

“...la mayoría de las representaciones de La Tunita no se hicieron para ser apreciadas a simple vista, se necesita buscarlas entre las oquedades de los afloramientos rocosos graníticos. Se trata de representaciones "ocultas" a las que tienen acceso únicamente quienes conocen el lugar o los guía alguna motivación particular" (2003a:35).

El principal conjunto pictórico de este sitio, el realizado en el interior de la cueva llamada La Sixtina, ilustra perfectamente lo que estamos indicando. La mayor parte de las impresionantes representaciones son visibles cuando uno se ubica en el interior, con la espalda prácticamente apoyada contra la pared rocosa del fondo, mientras que permanecen visualmente inaccesibles para un observador ubicado en la amplia explanada exterior.

Las dos cuevas relevadas en Campo de las Piedras por Segura (1970) miden, según este autor "un diámetro no mayor de dos metros en los costados" ( $\mathrm{p}$. 15) la primera, y $4 \times 2 \mathrm{~m}$ "la parte 


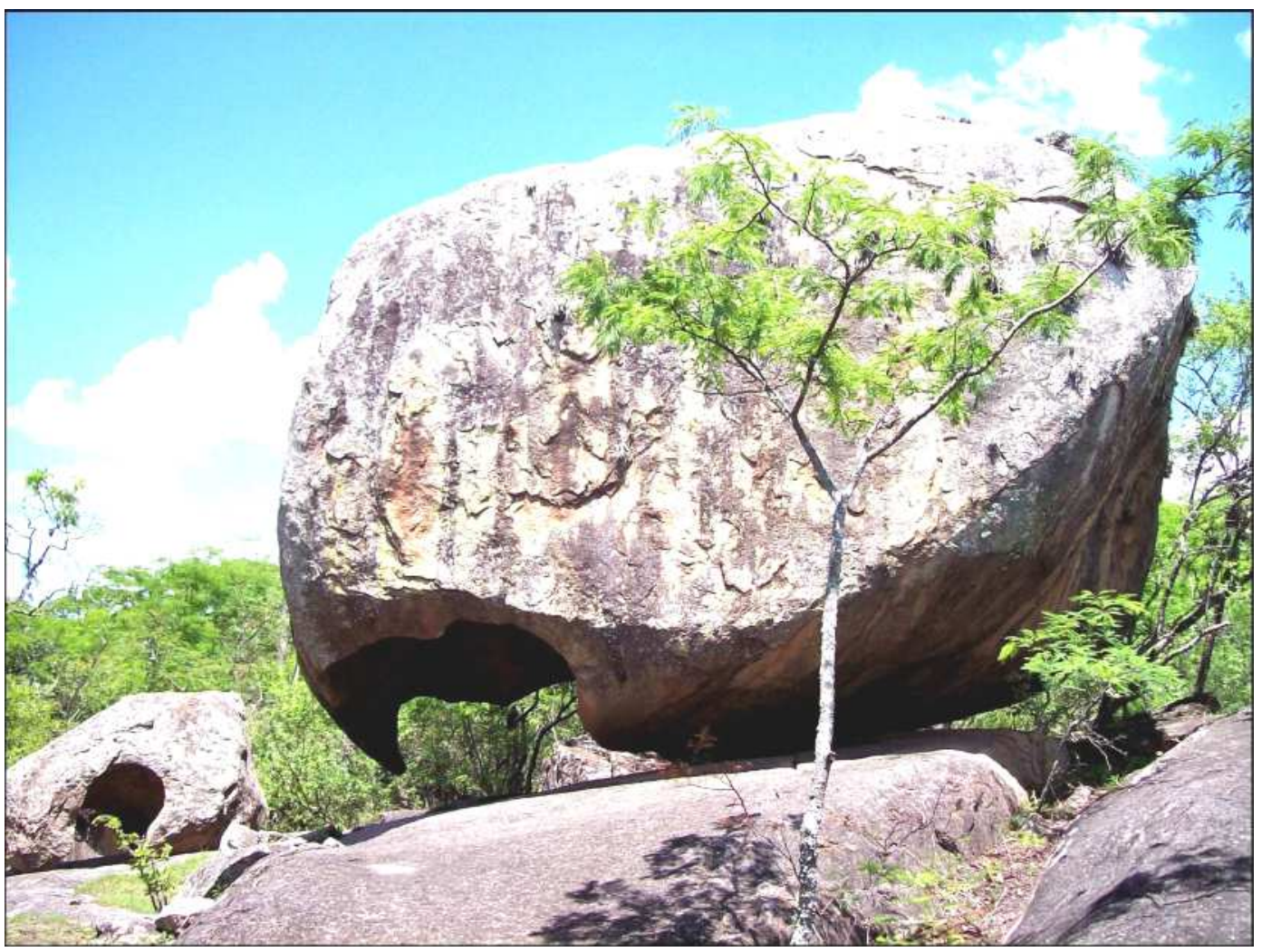

Figura 4. Cueva "La Sixtina" del sitio La Tunita

que da al suelo" (p. 16), la segunda. Señala también que el acceso al interior debe hacerse gateando y se queja porque el reducido espacio y la falta de luz motivaron el fracaso de sus fotografías. Al parecer también aquí parecen haber sido elegidos los espacios reducidos y menos accesibles física y visualmente.

Hay algunas evidencias de que esta restricción del acceso físico y visual a los motivos pintados pudo ser, en algunos casos, incrementada mediante la obturación de algunas de las entradas de las cuevas -en caso de tener más de una- con breves pircados de piedra, como en las Cuevas 1 y 6 de Oyola.

En La Tunita y Oyola se hallaron morteros tallados en rocas fijas en adyacencias o en el interior de una cueva, respectivamente. Parecen haber sido estos implementos, aparte de los motivos pintados y los pocos casos de obturación de accesos, los únicos acondicionamientos para la realización de las actividades que allí tomaban lugar. $\mathrm{O}$, por lo menos, son los únicos de los que perduraron vestigios materiales. La ausencia de estructuras asociadas a las pinturas también se verifica en Campo de las Piedras (Segura 1970:18). Tanto Segura (1970) como Gramajo y Martínez Moreno (1982) destacan que en Campo de las Piedras y Oyola, respectivamente, no hay evidencias arquitectónicas ni de otro tipo que pudiera indicar la existencia allí de viviendas. Más abajo nos explayaremos sobre este aspecto.

Entonces, la Modalidad 1 identificada en Oyola, Campo de las Piedras y La Tunita se caracteriza por una tendencia a la restricción de las posibilidades visuales y del número de 


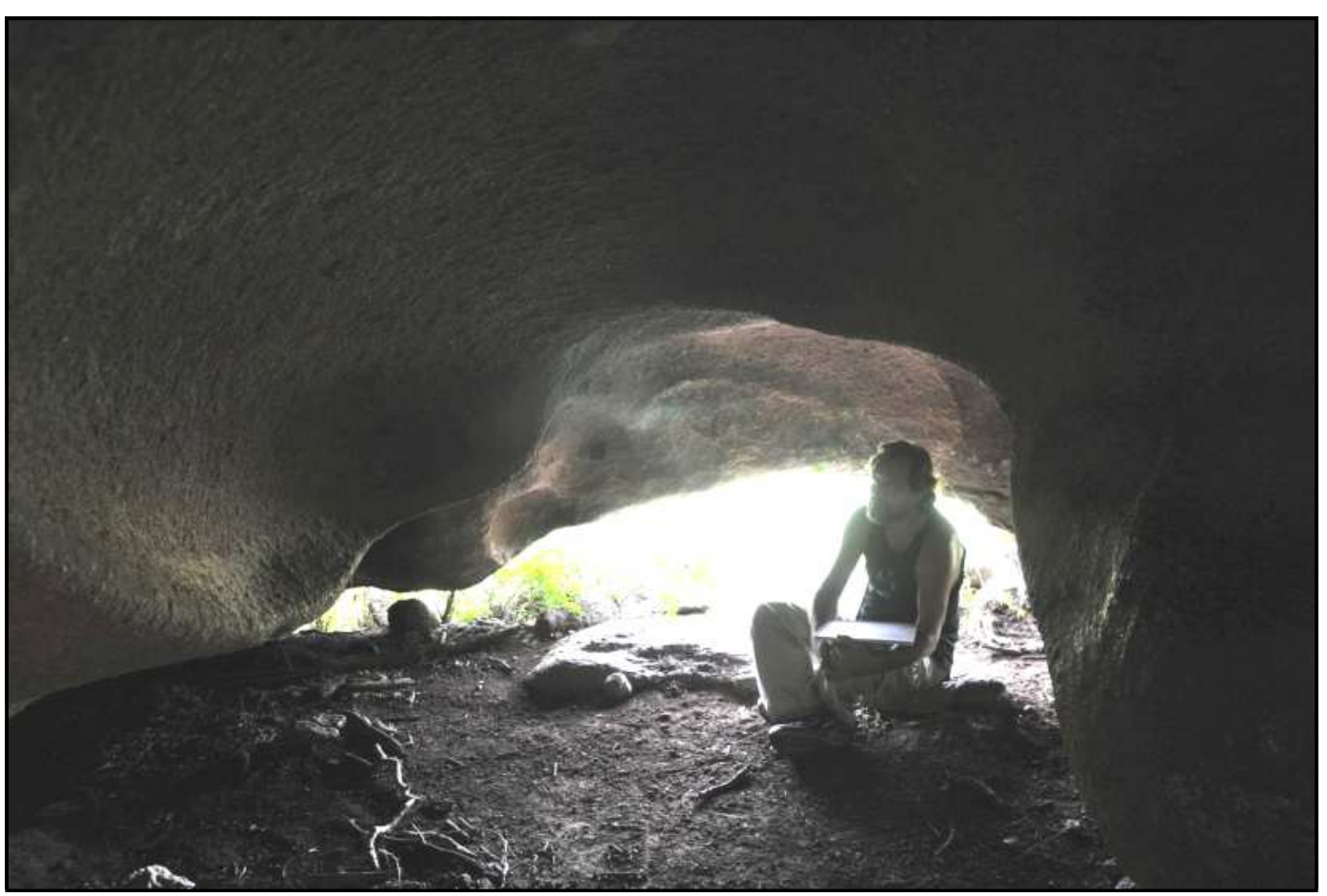

Figura 5. Interior de la Cueva 2 de Oyola cuyo techo se encuentra cubierto de alineaciones de puntos. Nótese el reducido tamaño del espacio elegido para realizar los motivos. Foto: Oscar Dechiara

observadores mediante el empleo de espacios interiores, pequeños y poco iluminados, por estar constituidos cada sitio por múltiples cuevas y por una separación visual y espacial de los sitios de vivienda y cultivo.

Modalidad 2: La Candelaria II o Cueva de la Salamanca, Casa Pintada de Guayamba, La Piedra con Pinturas de El Taco y Casa del Gallo

A diferencia de los sitios que incluimos en la Modalidad 1, los de la Modalidad 2 no se ubican sobre afloramientos rocosos de zonas elevadas sino que, por el contrario, se disponen en los sectores más deprimidos, a los lados de arroyos o en el interior de pequeñas quebradas. Las condiciones de visualización de los sitios son relativamente variables, ya que en los casos de La Candelaria II y Casa Pintada de Guayamba la topografía y la cerrada vegetación dificulta la visual hacia los sitios. En cambio, por ubicarse cerca de la cumbre, la vegetación que enmarca a La Piedra con Pinturas de El Taco es menos cerrada lo cual permite cierta mejor visualización del sitio desde la distancia. Por otro lado, estos sitios no involucran los impresionantes bloques de granito, sino que aquí se trata de afloramientos de rocas metamórficas mucho menos destacadas en relación al entorno. De igual modo, la visual desde los dos primeros sitios está muy limitada por la vegetación circundante y la topografía. En el caso de La Piedra con Pinturas de El Taco es posible una visión panorámica del arroyo que corre a un par de cientos de metros de distancia. Una diferencia muy importante con los sitios de la Modalidad 1 es que, al menos en los casos de Casa Pintada de Guayamba y La Piedra con Pinturas de El Taco, hay una gran proximidad con los sitios de vivienda. En el 
primero, una serie de recintos que pudieron haber sido de habitación se ubican a la misma altura en la ladera opuesta de la quebrada y a una corta distancia de modo que si bien la intervisibilidad es relativamente limitada no llega a ser nula y, además, probablemente por la disposición topográfica de ambos sitios, los sonidos producidos en cualquiera de ellos son fácilmente audibles en el otro ${ }^{3}$. En el segundo caso la cueva pintada se ubica a escasos $50 \mathrm{~m}$ de otro conjunto de recintos que, a juzgar por la arquitectura, podría corresponder a una vivienda. No está claro si esta proximidad entre las cuevas pintadas y las viviendas también se verifica en La Candelaria II ya que su entorno no ha sido prospectado aún.

Otra característica de la modalidad 2 es que sólo una cueva fue pintada en cada uno de los casos considerados, lo cual contrasta con los sitios de múltiples cuevas que veníamos describiendo para la modalidad 1. En el caso de La Candelaria II no puede asegurarse que esto fue efectivamente una elección ya que no se conocen cuevas relativamente cercanas. La Candelaria I o Casa del Gallo, otro alero con pinturas, dista de aquella unos $4 \mathrm{~km}$ según informa Segura (1988) y por ello podría ser considerado otro sitio. Sin embargo, en Casa Pintada hay otros aleros próximos que no fueron pintados. Incluso uno de ellos con características similares se ubica a sólo unos $20 \mathrm{~m}$ del que sí fue pintado. Lo mismo puede decirse de La Piedra con Pinturas de El Taco donde existen abrigos rocosos próximos al que alberga las pinturas pero que no fueron seleccionadas con ese fin.

Con respecto a las condiciones de visualización de los motivos pintados, en La Candelaria II la mayor parte de las representaciones se ubica en el interior de la gran cueva. Sin

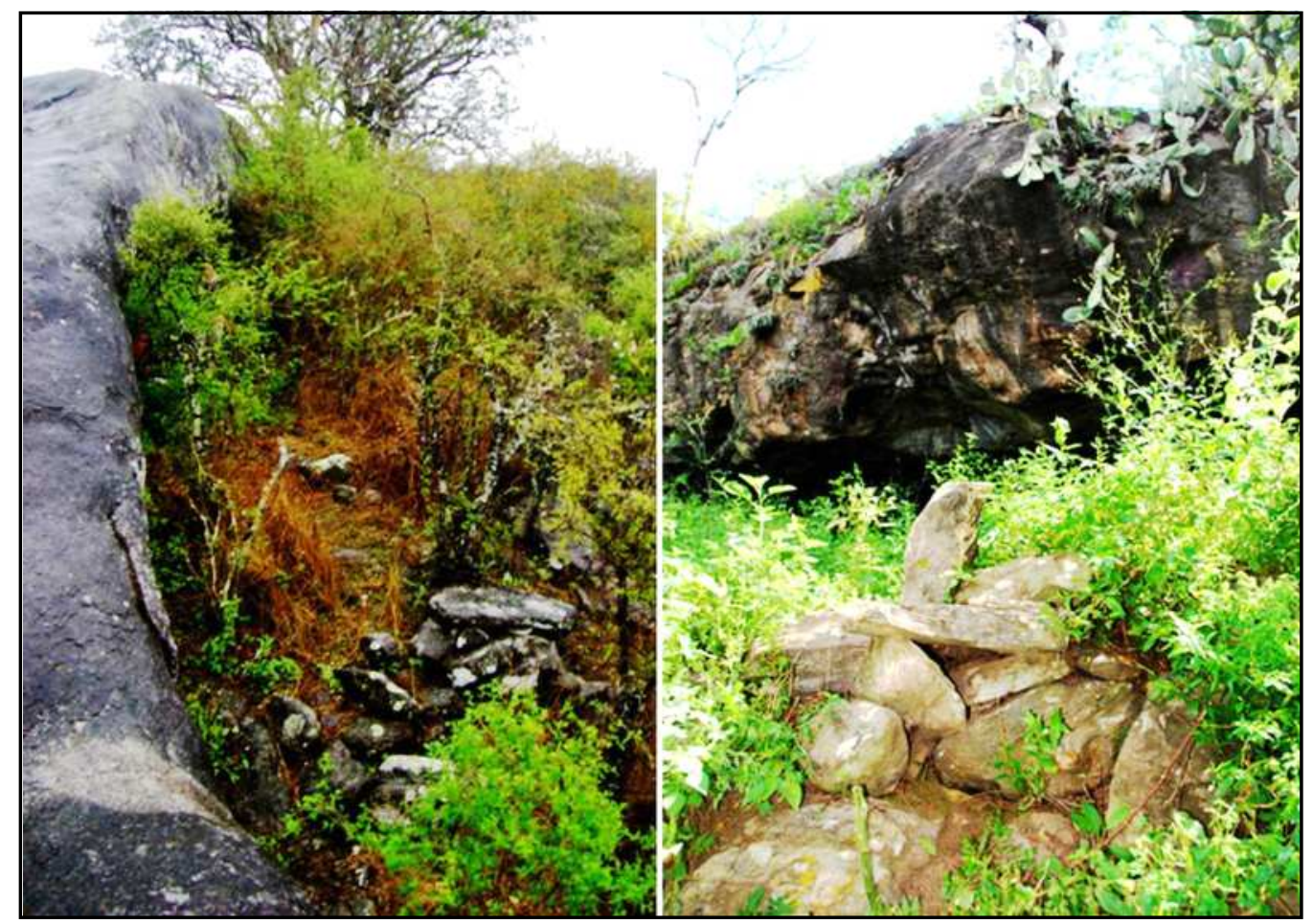

Figura 6. a. Aterrazamientos en el exterior de la Piedra con Pinturas de El Taco, a la izquierda, y b. La Candelaria II, a la derecha. 
embargo, sólo un pequeño sector ofrece una visión privilegiada de las figuras pintadas ya que, como indica Llamazares (1999-2000), éstas fueron ubicadas preferentemente en un espacio cóncavo del techo que adopta la forma de una cúpula. Entonces, si bien no hay una lógica de exclusión expresada en los mismos términos que los sitios descriptos anteriormente, es decir eligiendo cuevas pequeñas, podría interpretarse que pudo existir algo similar pero expresado no como una restricción física, sino de posibilidades visuales. Sin embargo, a diferencia de aquellos otros sitios, en La Candelaria II parte de las figuras son visibles desde el exterior (Llamazares 1999-2000), desde el frente de la cueva. Más aún, los diseños que se ubican en las irregularidades del techo de la gran caverna fueron plasmados sobre las caras que se orientan hacia la entrada indicando que desde allí debían ser vistas. En Casa Pintada de Guayamba y La Piedra con Pinturas de El Taco esta situación es aún más marcada pues allí todos los motivos son visibles desde el exterior sin que se pueda distinguir un lugar con ventaja visual. La importancia del exterior de la cueva en los tres casos de la Modalidad 2 que venimos caracterizando fue materialmente enfatizada por medio de la construcción de espacios nivelados, aterrazados mediante potentes muros de piedra justamente frente a la entrada de las cuevas (Figura 6 a y b). Además de estas plataformas aterrazadas cada sitio está provisto de un mortero. El de La Candelaria II se ubica, de modo sugestivo, precisamente bajo la somera cúpula del techo, aquella pequeña área visualmente ventajosa (Llamazares 1999-2000).

Quizá pueda agregarse a esta modalidad espacial la mencionada La Candelaria I o Casa del Gallo según la denominación dada por los pobladores del lugar. Se trata también de una sola cueva siendo los motivos visibles desde el exterior, incluso desde gran distancia. Sin embargo, carece de la plataforma exterior común a los demás sitios y desconocemos su vinculación a áreas de viviendas próximas. La adscripción a esta modalidad permanece como sólo una conjetura.

En síntesis, la Modalidad 2, característica de La Candelaria II (o Cueva de la Salamanca), Casa Pintada de Guayamba y La Piedra con Pinturas de El Taco, corresponde a sitios integrados por una única cueva con pinturas, sin marcada separación visual y espacial con sitios de vivienda, baja restricción de acceso visual a las pinturas desde fuera de las cuevas y la ampliación del espacio exterior mediante plataformas.

Modalidad 3: El Tipán, Puesto La Mesada y Rastro del Avestruz.

Aunque se ubiquen en posiciones topográficas diferentes los sitios de El Tipán, Puesto La Mesada y Rastro del Avestruz tienen en común que no muestran ningún principio de exclusión visual. El único friso de El Tipán se dispone sobre la cara vertical más o menos plana de un gran bloque rocoso situado sobre la terraza aluvial del arroyo que desciende por la quebrada de El Tipán hacia el Valle de Catamarca (Barrionuevo 1972). Puesto La Mesada consiste en, al menos, tres conjuntos de figuras grabadas en las superficies casi horizontales de grandes rocas aflorantes sobre las laderas de la quebrada del arroyo Los Dulces (Nazar 2003b). Se trata de un sector cercano a la cumbre de la serranía de El Alto-Ancasti en un espacio ecotonal entre el pastizal de altura y el bosque serrano, pero aún con amplios sectores abiertos. En tales condiciones no hay, al menos en la actualidad, vegetación que obstruya la visión hacia y desde los sitios. Distinto es el caso de Rastro del Avestruz que se ubica en un sector de bosque serrano, actualmente a la sombra de grandes cebiles. En el caso de El Tipán desconocemos las condiciones de visibilidad que presenta el sitio al cual, por otro lado, es muy difícil acceder. Pero en todos los casos, por estar al aire libre no hay 
restricciones físicas a la cantidad de personas que acceden visualmente a los motivos una vez que uno se aproxima a los bloques donde fueron realizados (Figura 7 a y b). No hemos hallado, ni se han reportado para ninguno de los tres sitios, la existencia de otras estructuras que pudieran haber formado parte del acondicionamiento del espacio en torno a ellos.

Hay dos aspectos adicionales, que si bien no tienen relación con la lógica espacial, distinguen a los sitios de la modalidad 3 de los de las modalidades 1 y 2 . Por un lado, se trata de representaciones logradas mediante grabado en surco profundo ${ }^{4}$, siendo esta una técnica totalmente ausente en los sitios en cuevas y, por otro lado, podría haber diferencias en los motivos representados, aunque esto último debe ser mejor estudiado.

La Modalidad 3 de El Tipán, Puesto La Mesada y Rastro del Avestruz no involucra cuevas o abrigos rocosos, sino que se trata de grabados sobre caras planas de bloques rocosos, generalmente en posición horizontal. La visualización hacia y desde los sitios es variable y aún no conocemos en qué medida se vinculan a otros tipos de sitios. No hay en esta modalidad restricción visual ni a la agregación de personas en torno a los motivos.

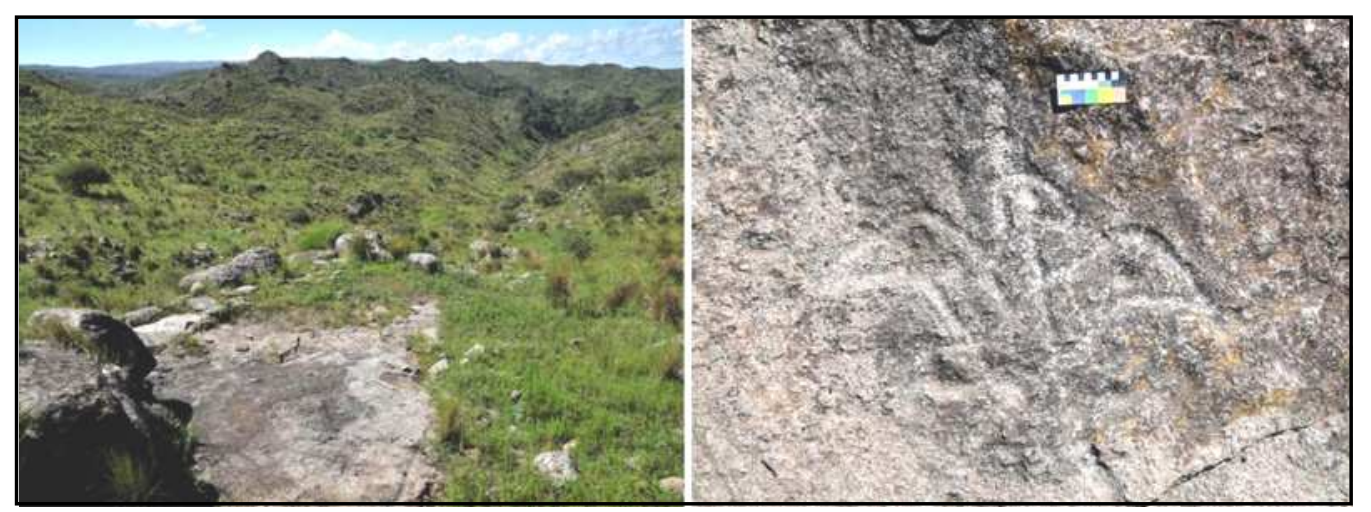

Figura 7. a. La piedra plana horizontal en la fotografía de la izquierda ejemplifica la forma de disposición de los bloques grabados en la Modalidad 3. Se trata de una de las tres localidades que conforman el conjunto de Puesto La Mesada. $b$. A la derecha, un detalle de uno de los motivos grabados en su superficie. Fotos: Oscar Dechiara

\section{Modalidad 4: Oyola}

La modalidad 4 ha sido definida en el sitio de Oyola donde también, recordemos, aparece representada la modalidad 1. A diferencia de esta, la modalidad 4 se caracteriza por que se seleccionaron como soportes las paredes de las cuevas más grandes, cuyo interior, además, es visible desde varias direcciones (Figura 8 a y b). También, al menos una de las cuevas fue materialmente acondicionada de manera notoria mediante la nivelación del piso por medio de un alto muro contenedor y amoblada con una mesa y banquetas de grandes rocas. Quizá funcionó como puesto para el manejo del ganado. Esta modalidad ha podido ser definida ya que los motivos representados corresponden a pinturas y grabados recientes ${ }^{5}$. Algunas de las inscripciones son fechas (febrero 1935) y otras fueron ejecutadas según el estilo de "marcas de ganado". No vamos a profundizar en esta cuarta modalidad rupestre. No porque no resulte de interés, pues su estudio seguramente iluminará interesantes aspectos de la historia local. Lo que nos interesa aquí es destacar que se trata de una lógica espacial diferente de aquella más antigua, la modalidad 1, aún cuando está organizada en 
un mismo entorno. Ello destaca lo que en realidad ya es evidente: que en la construcción de los espacios rupestres, si bien utilizaron elementos del entorno natural, lo hicieron bajo una lógica cultural.

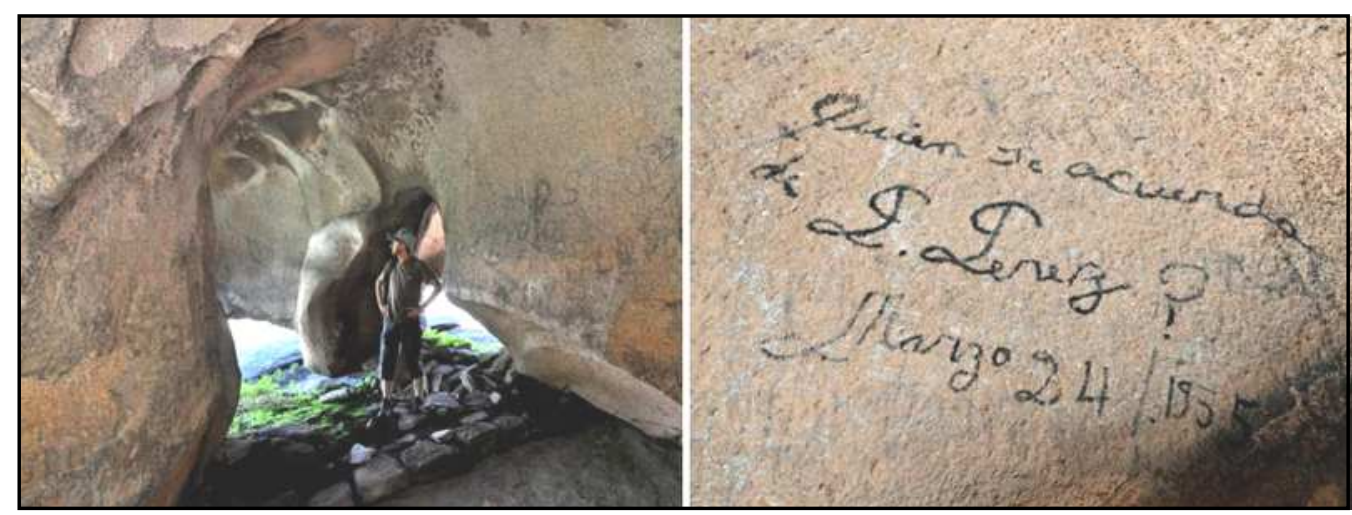

Figura 8. a. Cueva 5 de Oyola donde se ubican motivos de la modalidad 4. En esta cueva no se han hallado pinturas prehispánicas. Nótese la amplitud y luminosidad en su interior. b. A la derecha, un ejemplo de inscripción característica de esta modalidad. Fotos: Oscar Dechiara

Cronología.

Tenemos realmente pocos elementos de valor cronológico para ubicar en el tiempo las distintas modalidades espaciales del arte rupestre de las serranías de El Alto-Ancasti. A la escasez de investigaciones se suma una aún menor cantidad de fechados absolutos. Nuestra asignación cronológica deberá entonces ser considerada como preliminar y sujeta a correcciones.

Sabemos que la Modalidad 4 es relativamente reciente. Ya hemos indicado que algunos motivos corresponden a fechas. Quizá sea la más temprana, febrero de 1935, la que indica el comienzo de esta forma de espacialidad del arte rupestre. Los demás escritos son nombres, en ocasiones con el lugar de procedencia de la persona, declaraciones de amor y otras por el estilo. No hay problemas con esta asignación cronológica.

Las Modalidades 1 y 2 podrían ser más complicadas. Si bien se reconoce que una gran cantidad de motivos podrían ser, por criterios estilísticos, asignados a la cultura de la Aguada, esto no soluciona mucho la situación. En principio, porque aún no se conoce con precisión la cronología del fenómeno Aguada en las serranías de El Alto-Ancasti. Los únicos fechados absolutos, realizados sobre muestras de pigmento de 4 motivos de La Candelaria II, informan que fueron pintados en un lapso que va del 700 al 1300 d.C. (Llamazares 1999-2000). Se puede notar que tal cronología es concordante con la aceptada para el desarrollo del fenómeno conocido como Cultura de La Aguada o Período de Integración Regional (Gordillo 2007). No obstante, desde hace tiempo González (1977) viene sugiriendo la existencia de diferencias estilísticas en el arte rupestre de algunos sitios, entre ellos La Candelaria II y La Tunita, que podrían indicar diferencias cronológicas. Más recientemente advirtió que las diferencias estilísticas podrían ser mayores aún (González 1998). Quizá estas variaciones correspondan a diferentes momentos del período medio. Sin embargo, la reciente detección de sitios habitacionales con cerámicas que podrían ser pre-aguada como Los Corpitos y Los Pedraza (Dlugosz 2005), nos advierte sobre la posibilidad que algunos de estos estilos 
pudieran corresponder a momentos más antiguos. Falta aún encarar este tema de forma sistemática, realizar seriaciones y analizar superposiciones. El empleo del método de datación de pigmentos puesto en práctica en La Candelaria II (Boschín et al. 1999, Llamazares 1999-2000) debería ser extendido.

Por último, para la modalidad 3 carecemos totalmente de indicadores cronológicos. Podría ser contemporánea a las modalidades 1 y 2, pero también podría resultar interesante explorar la posibilidad que Puesto la Mesada, Rastro del Avestruz y El Tipán pudieran haber formado parte de paisajes más antiguos, quizá de cazadores recolectores, de los cuales conocemos aún muy poco pero cuya presencia aparece tímidamente indicada por puntas lanceoladas halladas en algunas localidades no muy alejadas, como Icaño (A.A.V.V. 1999), Vilismán (Gramajo de Martínez Moreno 2001) y Casa de Piedra (Serrano 1968). Sin embargo, esto último es por ahora sólo una conjetura.

\section{Arte Rupestre y espacios rituales en El Alto-Ancasti}

En base a lo dicho, no hay mucho más que podamos agregar, por ahora, a la caracterización de la Modalidad 3. En cambio, tenemos muchos más datos acerca del paisaje arqueológico contemporáneo a las modalidades 1 y 2 . Estas modalidades corresponden, además, a las representaciones que fueron generalmente consideradas como el arte rupestre característico de la cultura de La Aguada (De Hoyos 2007, González 1998, Gordillo 2009, Llamazares 1999-2000, entre otros). ¿A que se deben las diferencias en las modalidades espaciales observadas en estos sitios? A continuación intentaremos argumentar a favor de la hipótesis que las diferentes modalidades expresan espacialidades de distintas formas rituales. Pero, ¿cuáles serían estas formas? Creemos útil en este punto revisitar la obra de Víctor Turner (1999 [1967]). Este autor, recuperando la elaboración de Van Gennep (2008 [1909]) sobre los rites de passage, concibe esta forma ritual como un proceso conformado por tres fases: separación, margen o limen y agregación:

"La primera fase, o fase de separación, supone una conducta simbólica que signifique la separación del grupo o el individuo de su anterior situación dentro de la estructura social o de un conjunto de condiciones culturales (o "estado"); durante el periodo siguiente o período liminar, el estado del sujeto del rito (o "pasajero") es ambiguo, atravesando por un espacio en el que encuentra muy pocos o ningún atributo, tanto del estado pasado como del venidero; en la tercera fase, el paso se ha consumado ya" (Turner 1999: 104).

Estas tres fases son la estructura del proceso ritual. Son forma y no contenido. Su puesta en escena es histórica y culturalmente específica de cada contexto particular. Se trata de un esquema que creemos que podría resultar útil para comprender la lógica espacial de la Modalidad 1. Intentaremos a continuación argumentar porque pensamos así.

Si bien la fase de separación puede no implicar la separación física de los iniciados de su entorno social o la constitución de lugares rituales especiales, es muy frecuente que así sea (cf. Turner 1999). Tal como propone Rappaport, se trata de un recurso muy poderoso para lograr el efecto de ruptura con lo cotidiano: "tiempos y lugares especiales pueden, al igual que posturas y gestos extraordinarios, distinguir palabras y actos rituales de palabras y actos ordinarios. En el tiempo o lugar ritual, las palabras y los actos que pueden ser indistinguibles de los cotidianos adquieren a veces significados especiales" (1999:50) ${ }^{6}$. De allí que estos lugares rituales "sean 
a menudo inusuales, o destacados en varios aspectos. Pueden ser de difícil acceso, estar situados en lugares elevados o en lo profundo de cuevas, por ejemplo" (1999: 281)7. No son estas, claro, las únicas posibilidades de generar el efecto de ruptura con lo ordinario. Hay múltiples alternativas, de las cuales la etnografía de los ritos de paso podría dar buena cuenta (por ejemplo: Insoll 2004 y Turner 1999, entre otros). Lo principal que debemos retener aquí es la idea de la ordenación del entorno ritual con el fin de generar un sentido de separación, de discontinuidad con aquello que resulta habitual.

Podríamos considerar que quizá haya sido la búsqueda de lograr este efecto de ruptura que los espacios rupestres de la Modalidad 1 ocuparon lugares separados de aquellos donde se realizaba más cotidianamente la reproducción de las estructuras sociales y donde las personas asumían los roles que le eran asignados en su grupo social. Ya hemos indicado que es común a todos los sitios de esta modalidad la ausencia de estructuras que pudieran haber formado parte de viviendas. No se trata de una separación expresada en una gran distancia o dificultad de acceso sino, en primer lugar, en una inaccesibilidad visual desde y hacia los sitios con arte rupestre. Es interesante aquí notar que este efecto se logró en la modalidad 1 ubicando los sitios en lugares elevados en la cima de los afloramientos. En segundo lugar, en los dos sitios de esta modalidad en los cuales se han practicado excavaciones: Oyola y La Tunita, han arrojado resultados muy magros (Gramajo y Martínez Moreno 1982, Jorge Reales com. pers. 2009). Gramajo destaca el contraste entre la escasez de material en los sitios de arte rupestre de Oyola en relación a las "zonas bajas y aledañas, en los barreales, tierras utilizadas para agricultura" (2001:28), donde en cambio sí se recuperó abundante material. Segura (1970) informa en relación a una de las cuevas de Campo de la Piedras que "en los alrededores no hay señales de habitación, ni de sembradios, ni nada que nos haga presumir que haya estado habitado" (p. 16) y luego añade respecto a otra de las cuevas que "en los alrededores de ella no hay señales de viviendas, de cultivos, de paredes, fogones, etc.; tampoco se encontró trozos de cerámica, artefactos de piedra, etc." (p.18). Estos datos podrían indicar que, aún cuando no había una restricción física de acceso a los sitios, estos no eran de todos modos intensamente ocupados. Podríamos suponer entonces que no eran parte de los espacios donde tenían lugar las prácticas más habituales destinadas a la reproducción cotidiana y, quizá, el acceso a ellos estaba de alguna forma socialmente restringido.

En tercer lugar, los lugares seleccionados para montar los entornos rupestres de la Modalidad 1 tienen un marcado efecto escenográfico. Los enormes bloques de granito no son comunes al paisaje de El Alto-Ancasti, por el contrario, corresponden a aflojamientos localizados en pocos espacios relativamente restringidos (Aceñolaza et al. 1983), y su abrupta aparición sobre el follaje es capaz de crear un fuerte sentido de ruptura con la experiencia cotidiana. Es interesante aquí recuperar las primeras expresiones con las cuales otros investigadores han caracterizado estos lugares. Según Gramajo y Martínez Moreno (1982:78) en Oyola "los abrigos que se destacan en el pintoresco paisaje afectan la forma de grandes hongos". Por su parte, Segura se refiere a la cuevas de Campo de las Piedras en los siguientes términos "Parecen, en algunos casos, grandes caparazones de tortugas o paraguas, sin mango asentado, con la concavidad hacia abajo (sic)" (1970:14). El dato aquí no es si los enormes bloques pétreos parecen hongos, caparazones o paraguas sin mangos, sino que los autores citados hayan tenido que recurrir a imágenes surrealistas para poder describir ese paisaje que experimentaban como extraño. Otros han sido menos figurativos sin poder, a pesar de ello, esconder la sensación de asombro causado por estas grandes rocas: "Los abrigos rocosos que cobijan estos importantes testimonios arqueológicos emergen del corazón del bosque de Cebil presentando extrañas y enigmáticas formas" (Nazar 2003a:31). 
No pretendemos que la experiencia de los investigadores de arte rupestre pueda ser equivalente a la de quienes en el pasado participaban de las prácticas rituales en aquellos espacios rupestres. Pero sí es posible imaginar que los recursos empleados para provocar una ruptura con la experiencia cotidiana, que acabamos de describir, a los que debería sumarse la ansiedad e incertidumbre propias de quien está por atravesar una experiencia transformadora, podrían haber sido medios eficientes y suficientes para inspirar un profundo sentido de diferencia con la experiencia ordinaria. Las formas sociales habituales habían quedado atrás. La fase de separación que iniciaba el proceso ritual se había completado. En esta situación, quienes participaban del ritual estaban en condiciones de ser introducidos a otras realidades diferentes a aquellas.

Turner ha indicado que el núcleo fundamental de la etapa liminar del proceso ritual está definido por la comunicación de una realidad alternativa constituida por elementos conocidos pero ordenados de acuerdo a estructuras completamente nuevas. Esta comunicación, continua diciendo Turner, tiene tres componentes: "1) exhibiciones, "lo que se muestra"; 2) acciones, "lo que se hace", y 3) instrucciones, "lo que se dice"" (1999:113-114). Estos tres componentes son sólo analíticamente separables ya que en la práctica aparecen inextricablemente unidos. Es interesante de todos modos traerlos a la discusión para reflexionar acerca de las posibilidades que una visión arqueológica puede tener para conocer aspectos de cada uno de ellos. Resultan evidentes las limitaciones que nuestra disciplina tiene para reconocer en la cultura material "aquello que se dijo" ${ }^{8}$. Quizá el avance en los estudios iconográficos e iconológicos nos ayude a realizar propuestas cada vez menos especulativas sobre los sentidos narrativos que pudieron haberse articulado con las pinturas.

No es aventurado pensar que los principales objetos exhibidos eran las pinturas mismas, pero también es posible que las prácticas en estos sitios hayan involucrado la exhibición de una variada parafernalia ritual. Por ejemplo, vistosas vestimentas, instrumentos musicales (Gudemos 2003), elementos para la preparación y consumo de sustancias alucinógenas (Llamazares 1999-2000), la elaboración de pigmentos o, incluso, objetos rituales relativamente fijos (estelas) confeccionados con madera u otros materiales que no se conservaron hasta hoy. Las prácticas involucradas en el período liminar eran, con seguridad, mucho más complejas y elaboradas que lo que nos proporcionan los datos arqueológicos.

Quizá podamos aventurarnos un poco menos especulativamente en la reconstrucción de las acciones que tenían lugar en estos espacios rupestres ya que conocemos los contextos y las posibilidades y limitaciones que estos ofrecían a las prácticas. Vamos a asumir que una parte importante del ritual, sino la más importante, era la de revelar a los iniciados los misterios contenidos en los decorados techos de las cuevas. Ello implicaba que debían ser vistos. Esto es común para las dos modalidades espaciales que venimos analizando. Sin embargo, es posible argüir que hubo marcadas diferencias en la forma en que ello sucedía en cada una de estas.

Ya dijimos que es característico de la Modalidad 1 que cada sitio está constituido por varias cuevas con pinturas. Ello indica que es posible pensar que la participación en el ritual pudo implicar la visita secuencial a las distintas cuevas. Es decir, que la comunicación de los conocimientos contenidos en estos espacios pudo tomar la forma de un recorrido que conectaba lugares de alta significación. Por otro lado, el hecho de que las cuevas pintadas son pequeñas, una elección deliberada que buscaba conformar espacios íntimos, nos hace pensar en grupos también pequeños de personas, quizá no mayores al integrado por un 
iniciado y su maestro. Lo cierto es que no se trata de ámbitos acondicionados para el despliegue público de las pinturas como sí podría pensarse para la Modalidad 2. Falta aún mucha investigación. Lo relatado sólo son pequeños indicios de puestas en escena que debieron ser extraordinariamente más elaboradas y ricas en detalles. Mediante éstas los iniciados eran instruidos en aspectos de importancia para las nuevos roles que les tocaría asumir en su nuevo estado. La persona que había sido ya no era, el rito de paso, por definición, había operado una transformación ontológica. En la fase de agregación otra persona regresaría al seno de la comunidad.

No hay, por ahora, forma de saber cuál era el estado de las personas antes y luego de atravesar el rito de paso. Para el caso, De la Fuente (1990) propuso que La Tunita podría tratarse de un lugar de iniciación chamánica. Carecemos de información para apoyar o refutar esa hipótesis o cualquier otra. Sólo podemos indicar que las transformaciones en la vida de las personas en las llamadas "sociedades primitivas", y también en las "modernas", que son marcadas ritualmente, son múltiples. Un repaso rápido por la literatura etnográfica nos provee de ejemplos sobre ritos de pubertad, de iniciación guerrera, funerarios, etc.

Claramente, la Modalidad 2 corresponde a una forma muy distinta de organizar el espacio ritual y en gran medida contrapuesto a la Modalidad 1. En primer lugar porque no parece ordenado en función de provocar ese sentido de discontinuidad que buscamos fundamentar para esta última. Por el contrario, estos sitios suelen aparecer muy próximos a los espacios de actividades más cotidianos -las casas- $y$, sobre todo, manteniendo un considerable contacto visual y auditivo. Además, en la Modalidad 2 el arreglo espacial parece estar guiado, antes que por una lógica de restricción del acceso físico y visual, por una de inclusión y agregación: los motivos no sólo permiten ser vistos desde afuera de la cueva, sino que además este espacio exterior fue intencionalmente modificado de modo que pudiera albergar un número mayor de participantes en el ritual y/o actividades que, como la danza, requieren de cierto espacio para ser ejecutadas. También es posible entender que la forma que pudo haber seguido la práctica ritual fue diferente en esta modalidad ya que, por tratarse en todos los casos de sólo una cueva, estos escenarios no podrían haber admitido un recorrido similar al que pudo haber tomado lugar en los sitios organizados según la Modalidad 1.

Los espacios rupestres de la Modalidad 2 recuerdan más a formas rituales como las que aparecen descritas con cierto detalle en las fuentes documentales del período colonial bajo la denominación general de "juntas y borracheras" y quizá eran escenarios de formas prehispánicas de estos rituales ${ }^{9}$. Con tal designación se hacía referencia a ceremonias que tomaban lugar para una variedad de ocasiones: la colecta de la algarroba, el fallecimiento de un miembro de la comunidad, la organización para una batalla, etc. (Castro Olañeta 2006, Farberman 2005). Aunque el pasaje es largo, vale la pena reproducir la descripción que proporciona el Padre Lozano de una de estas reuniones entre los Lules:

"La víspera de la borrachera una hora depues de aver anochecido concurren a una plazuela los Indios, e Indias, que han de beber: en ella tienen un palo clavado, junto al cual está en pie la mujer o hija del que hace la fiesta con un baculo, o caña en la mano, de cuya extremidad está pendiente multitud de uñas de Javalies y venados, que remedan el son de los cascabeles, y esta es la que lleva el compas de los que han de cantar dando con la punta del baculo golpean en el suelo, y en comenzando esta prosiguen los varones con el canto puestos en fila, y tras ellos las mujeres tambien en fila. El que tiene mejor voz de los varones, guia el canto, $y$ andan dando vueltas al rededor de aquel palo 
saltando y brincando al mismo compas del canto ni mas ni menos que una manada de yeguas cuando trillan una era de trigo [... van a las casas de lo que hacen la bebida, y puestos en frente de ellas en alguna distancia ordenados por fila, como diximos, guiando siempre la del compas, comienzan otra vez su canto y bayle, que dura, o hasta que han consumido totalmente la bebida, o están del todo beodos y privados del juicio, que se caen por los suelos..." (Lozano 1733:102-103).

Otras descripciones dan cuenta de una riquísima variedad de gestos, vestimentas y parafernalia ceremonial. Como ejemplo reproducimos el siguiente pasaje de un expediente judicial de los indios de Quilino de principios del siglo XVII publicado por Castro Olañeta (2006:164):

"...y una noche hallo que en el dicho pueblo estavan los yndios en una borrachera y bio que tenian echo un zerco de ramas y dentro del por un callexon que tenian echo de ramas danzazan [sic] con [...] unos papagayos y figuras de lagartos y dixeron que allí avia una biexa desnuda con pellexos de tiguere...".

Nótese que en este relato se hace referencia además a la exhibición durante la ceremonia de animales y figuras de animales, que incluso figuran en el repertorio pictórico de varios de los sitios con arte rupestre considerados en este trabajo. Como estas, podemos hallar un gran número de descripciones de las formas posibles que tomaron este tipo de ceremonias, pero las transcriptas aquí alcanzan para destacar ciertos elementos comunes a esta forma ritual. En primer lugar su carácter colectivo y convocante, en segundo lugar la existencia de espacios abiertos que permitieran la realización de la danza, la exhibición de animales y figuras de animales y, por último, que no hay necesariamente una separación de las áreas de viviendas ${ }^{10}$. Se trata ciertamente de las características que definen la modalidad $2^{11}$.

No conocemos que sucedía en las cuevas en ninguna de las modalidades ${ }^{12}$. Las excavaciones realizadas allí no proporcionaron datos suficientes para reconstruir las actividades que tomaban lugar en estos contextos. Los morteros presentes en algunas de ellas podrían haber sido utilizados para procesar alucinógenos consumidos en esas ocasiones, como sostiene una hipótesis chamánica (Llamazares 2004). También pudieron estar destinados a la preparación de los pigmentos con los cuales fueron pintados los diseños, o quizá a ambas cosas, lo que explicaría además como llegó la sustancia alucinógena a formar parte de los pigmentos (Maier et al. 2007).

\section{Discusión y Conclusiones}

Como en todo fenómeno cultural, hay varias escalas de tensión entre lo general y lo particular en el arte rupestre de El Alto-Ancasti. Nos interesa destacar tres de estas escalas por la relevancia que tienen para este trabajo. En primer lugar, la tensión entre aquello que es reconocido, de una manera bastante uniforme, como el "arte rupestre aguada" o más en general como arte rupestre de Ancasti y las diferencias en sus modalidades espaciales. Este aspecto fue el que más atención recibió aquí así que no vamos a profundizar en su discusión. Pero sí resulta de importancia en este punto considerar las otras dos escalas pues permiten reconocer los alcances y límites de la definición de las modalidades espaciales presentadas en este texto. Por un lado debemos tener en cuenta que las modalidades espaciales no reúnen sitios que son iguales, sino sitios que se organizan espacialmente compartiendo ciertos principios generales de inclusión/ exclusión, posibilidades visuales, etc. Sin embargo, en cada caso 
estos esquemas generales suceden de maneras particulares. Rápidamente podemos notar que hay diferencias internas en, por ejemplo, la cantidad y ubicación de cuevas, cantidad de morteros, iconografía y técnicas de confección de los motivos, entre otros aspectos. Es decir cada sitio expresa en este sentido una instancia de negociación entre lo general y lo particular, entre estructura y práctica. Pero además, algunos sitios de ambas modalidades muestran elementos que se escapan de la generalidad. Por ejemplo, en Oyola dos de las 17 cuevas con pinturas se disponen en lugares bajos próximos a las terrazas aluviales donde al parecer se ubicaban las viviendas contemporáneas lo cual no es enteramente coincidente con los principios que permitieron definir la Modalidad 1. Por otra parte, en algunas de las cuevas de este mismo sitio las pinturas son visibles desde el exterior, aunque en tales casos ese mismo exterior se halla limitado por la topografía u otros bloques rocosos. De igual modo, en La Candelaria, si bien las pinturas pueden ser observadas desde muchas direcciones, incluso desde el exterior, un rasgo que propusimos caracteriza a la Modalidad 2 , existe un sector del interior de la cueva con claras ventajas visuales que no podría haber sido ocupada sino por sólo unos pocos individuos simultáneamente, lo que parece más relacionado a las condiciones de visibilidad de la Modalidad 1.

¿Cómo interpretar estas excepciones, los contraejemplos, estos casos que se apartan de lo general? Las diferencias estilísticas en varios de los sitios y la larga cronología indicada por las dataciones de los motivos pintados en La Candelaria II, los numerosos casos de superposiciones y las diferencias en la composición química de las pinturas detectadas por nosotros en Oyola (Quesada y Gheco 2010), entre otros elementos, nos advierten acerca de la posibilidad que estos escenarios rupestres fueran permanentemente transformados. De modo que, y esta es la otra escala de tensión a la que hacíamos referencia antes, tampoco sería correcto pensar en cada sitio como formas particulares pues lo que en realidad parece ocurrir es que son resultados de procesos, quizá prolongados, de sucesivas eventos de agregación de pinturas y en estos siempre quedaba un lugar para la agencia, la interpretación creativa. Conocemos poco aún sobre estos procesos, su inicio, su duración, su ritmo. Pero parece claro que a lo largo del tiempo nuevos diseños eran agregados y los viejos eran reinterpretados en el marco de nuevas narrativas y la necesidad o búsqueda de otras formas de visualización y experiencias corporales. En los muchos siglos transcurridos varias generaciones de maestros, iniciados y danzarines beodos dieron forma a los escenarios rituales al tiempo que ellos mismos eran formados y transformados por esos mismos órdenes espaciales.

\section{Agradecimientos:}

Los viajes de reconocimiento de varios de los sitios arqueológicos mencionados en este artículo fueron financiados por el Fondo Nacional de las Artes, la Secretaría de Ciencia y Tecnología de la Universidad Nacional de Catamarca y el FONCYT. Una versión anterior fue presentada en el VIII Simposio Internacional de Arte Rupestre donde recibió importantes aportes de parte de los participantes. Pablo Cruz, Inés Gordillo y Alejandra Korstanje y dos evaluadores anónimos realizaron valiosos comentarios y sugerencias que contribuyeron a mejorarlo substancialmente. Agradecemos a Silvana Urquiza y Andrea Recalde por la invitación a participar de este número de la revista.

Los autores conservamos la responsabilidad por las ideas vertidas en este artículo.

\section{Notas}

${ }^{1}$ Aunque siempre queda la posibilidad de que el monte que rodea las cuevas haya sido talado. El frecuente hallazgo de hachas de piedra en distintos sectores de las serranías indican que se disponía de las herramientas necesarias. Sin embargo, no contamos aún con ninguna evidencia de tal actividad en torno a los sitios con arte rupestre. 
${ }^{2}$ Campo de las Piedras es un sitio de extensión notable con numerosas cuevas. Su estudio es aún muy superficial por lo cual, salvo por la breve caracterización de Segura y los pocos datos que agregamos aquí, permanece virtualmente desconocido. El monte donde se halla es muy cerrado lo cual dificulta enormemente el tránsito y la visión. Una prospección intensiva muy probablemente proporcionará datos de un gran número de cuevas con pinturas aún no conocidas arqueológicamente.

${ }^{3}$ Le debemos a Inés Gordillo estas importantes observaciones (comunicación personal, 2010).

${ }^{4}$ No se descarta que los grabados pudieron haber estado también pintados.

${ }^{5}$ Aunque no es la cronología lo que define la modalidad 4 sino su distribución espacial y forma de exhibición. Si en el futuro logramos afinar las cronologías de las pinturas y grabados de las demás modalidades quizá podamos caracterizar otras lógicas espaciales o descartar alguna de las definidas aquí.

${ }^{6}$ Traducción de los autores.

${ }^{7}$ Idem nota 7.

${ }^{8}$ Carlo Severi (2010) propuso recientemente que las pictografías amerindias deben ser entendidas como objetos mnemónicos que cobran significación en el marco de construcciones orales (aunque también podrían ser interpretaciones corporales como gestos o danzas) que a su tiempo perviven en la medida en que encuentran referentes duraderos en los motivos pictográficos que las evocan.

${ }^{9}$ Aunque nada dice que estos espacios rupestres no pudieron estar activos durante, al menos parte, del periodo colonial.

${ }^{10}$ Esto último no es tan común en las descripciones, probablemente porque como indican Castro Olañeta (2006) y Farberman (2005) estos rituales colectivos de origen prehispánicos fueron desde temprano combatidos por el poder colonial. Primero criminalizados y luego demonizados continuaron siendo practicados clandestinamente pero ahora en lugares ocultos, alejados de la mirada española, dando lugar a las "salamancas" conocidas en el folklore popular. Farberman (2005) y Grosso (2008) hicieron excelentes análisis de este devenir. Gordillo (2011) relata un caso similar, pero más reciente, de proscripción por parte de misioneros anglicanos de ceremonias tobas con cantos y consumo de alcohol en el Chaco Oriental. También en este caso se siguieron practicando en la espesura del monte.

${ }^{11}$ González (1998) propuso antes que nosotros, pero por motivos diferentes, que La Candelaria II podría haber sido el ámbito para la realización de la "danza del suri”, que considera se trataría de una ceremonia propiciatoria. Por su parte, Gudemos (2003) vincula este mismo sitio con las "juntas y borracheras" documentadas para los siglos XVI y XVII, y considera también el carácter propiciatorio que estas celebraciones podrían haber tenido. Ambos basan sus interpretaciones en una magnífica escena pintada en el techo de la cueva que representa una gran cantidad de individuos danzando mientras otros parecen estar golpeando un gran tambor. En medio de la escena hay una bandada de avestruces y sobre los personajes danzantes un gran felino acollarado.

${ }^{12}$ Además de las acciones de pintar y mirar los motivos rupestres, por supuesto.una primera caracterización general de la localidad y proponer una secuencia cronológica preliminar para el arte rupestre.

\section{Bibliografía citada}

Aceñolaza, F., H. Miller y A. Toselli.

1983. Las rocas cristalinas de la sierra de Ancasti en el contexto de las sierras pampeanas septentrionales. En Geología de la Sierra de Ancasti, editado por F. Aceñolaza, H. Miller y A. Toselli, pp. 13-22. Münstersche Forschungen Zur Geologie und Palaeontologie 59, Münster.

A.A.V.V. 1999. Vida e Historia de Nuestra Comunidad. El departamento La Paz en el este catamarqueño del noroeste argentino. Editorial Sarquís, San Fernando del Valle de Catamarca. 
Barrionuevo, O.

1972. La piedra pintada del Tipán. Dpto. Capayán, Catamarca. En: Cuadernos de Antropología Catamarqueña, 5. Catamarca.

Battaglia, A. A.

1982. Descripción geológica de las hojas 13f, Río Hondo; 13 g, Santiago del Estero; 14 g, El Alto; 14 h, Villa San Martín y 15 g, Frías. Provincias de Santiago del Estero, Catamarca y Tucumán. Carta geológico-económica de la República Argentina. Escala 1:200.000. Servicio Geológico Nacional, Buenos Aires.

Boschín, M. T., M. T. R. Hedges y A. M. Llamazares.

1999. Dataciones absolutas de arte rupestre de la Argentina. Ciencia Hoy Vol 9 N 50.

Castro Olañeta, I.

2006. Transformaciones y Continuidades de Sociedades Indígenas en el Sistema Colonial. El Pueblo de Indios de Quilino a Principios del Siglo XVII. Alción Editora, Córdoba.

De Hoyos, $\mathrm{M}$.

2007. Imágenes Contrapuestas. Las Manifestaciones Rupestres de las Sociedades Aguada y de Desarrollos Regionales. En Resúmenes Ampliados del XVI Congreso Nacional de Arqueología Argentina, Tomo II, pp. 427-433. EdiUnju, San Salvador de Jujuy.

De la Fuente, N.

1990. Nuevos Descubrimientos de Arte Rupestre en la Región de Ancasti, Provincia de Catamarca. Revista del Centro de Estudios de Regiones Secas, Tomo VII: 3-6. Tucumán.

De la Fuente, N. y A.R. Díaz Romero.

1979. Algunos motivos del arte rupestre de la zona de Ancasti (provincia de Catamarca). En: Miscelánea de arte rupestre de la República Argentina. Monografía de arte rupestre. Arte Americano Nro.1.:37-59. Barcelona.

Dlugosz, J. C.

2005. Prospecciones arqueológicas en los sitios Los Pedraza y Los Corpitos, Dpto. El Alto, Pcia. de Catamarca. Trabajo Final de la Carrera de Arqueología. Facultad de Ciencias Naturales e Instituto Miguel Lillo. Universidad Nacional de Tucumán. San Miguel de Tucumán.

Farberman, J.

2005. Las Salamancas Mestizas. De las Religiones Indígenas a la Hechicería Colonial. Santiago del Estero, Siglo XVIII. Memoria Americana 13:117-150.

González, A. R.

1977. Arte Precolombino de la Argentina. Introducción a su historia cultural. Ed. Valero. Buenos Aires.

1998. Cultura la Aguada, arqueología y diseños. Ed. Valero. Buenos Aires.

Gordillo, G.

2011. Lugares de diablos. Tensiones del espacio y la memoria. Prometeo, Buenos Aires. 
Gordillo, I.

2007. Eran Otros Tiempos. Cronología de la Integración Regional en el NOA. En Sociedades Precolombinas Surandinas. Temporalidad, Interacción y Dinámica Cultural del NOA en el Ámbito de los Andes Centro-Sur, editado por V. Williams, B. Ventura, A. Callegari y H. Yacobaccio, pp. 221-233. Buenos Aires.

2009. Imágenes quietas y símbolos viajeros. Representaciones rupestres y mobiliares en el arte Aguada oriental. Informe final inédito al Fondo Nacional de las Artes. Buenos Aires.

Gramajo de Martínez, A.

2001. Solar de mis Mayores. La Concepción del Alto. Ediciones V Centenario, Santiago del Estero.

Gramajo, A. y H. Martínez Moreno.

1982. Otros aportes al arte rupestre del este catamarqueño. Estudio 3: 77-88. Museo arqueológico Emilio y Duncan Wagner. Santiago del Estero.

Grosso, J. L.

2008. Indios Muertos, Negros Invisibles. Hegemonía, Identidad y Añoranza. Encuentro Grupo Editor, Córdoba.

Gudemos, M.

2003. ¿Una danza de integración regional en las pinturas rupestres de La Salamanca? Revista Española de Antropología Americana 33:83-119.

Insoll, $\mathrm{T}$.

2004. Archaeology, Ritual, Religion. Routledge, Londres y Nueva York.

Llamazares, A. M.

1999-2000 El arte rupestre de la cueva La Candelaria, provincia de Catamarca, Argentina. Publicaciones del CIFFYH 50:1-26.

2004. Arte chamánico: visiones del universo. En El lenguaje de los dioses. Arte, chamanismo y cosmovisión indígena en Sudamérica, editado por A. M. Llamazares y C. Martínez Sarasola, pp.. 67-125. Biblos, Buenos Aires.

Lozano, $\mathrm{P}$.

1733. Descripción Chorographica del Terreno, Ríos, Árboles y Animales de las Dilatadísimas Provincias del Gran Chaco Gualamba: y de los Ritos y Costumbres de las Innumerables Naciones Bárbaras e Infieles, que le Habitan con una Cabal Relación Histórica de lo que en Ellas han Obrado para Conquistarlas Algunos Gobernadores y Ministros Reales: y los Misioneros Jesuitas para Reducirlas a las Fe del Verdadero Dios. Córdoba, Colegio de la Asumpción.

Maier, M.; A. M. Llamazares y S. Parera.

2007. Nuevos hallazgos de componentes psicoactivos en pinturas rupestres de la Provincia de Catamarca, Argentina. Poster presentado al 2do Congreso Argentino y 1ro Latinoamericano de Arqueometría. Buenos Aires.

Nazar, D. C.

2003a. Parque Arqueológico La Tunita. Puesta en Valor Integral del Arte Rupestre de la Vertiente Oriental de la Sierra de Ancasti, Provincia de Catamarca, República Argentina. Tesis de Maestría 
inédita. Universidad Internacional de Andalucía, Sede Iberoamericana Santa María de La Rábida, La Rábida.

2003b. Relevamiento arqueológico de la zona austral de la Sierra de Ancasti (Provincia de Catamarca). CENEDIT, Universidad Nacional de Catamarca, San Fernando del Valle de Catamarca.

Quesada, M. y L. Gheco.

2010. Estructura y Práctica en el Arte Rupestre de las Sierras de El Alto-Ancasti (Catamarca, Argentina). Actas del VIII Simposio Internacional de Arte Rupestre, pp. 30-33. IAM/ISES, UNT/ CONICET, San Miguel de Tucumán.

Rappaport, R.

1999. Ritual and Religion in the Making of Humanity. Cambridge University Press. Cambridge.

Segura, A. B.

1970. Pictografías de Catamarca. Boletín de la Junta de Estudios Históricos de Catamarca 19601968: 11-33.

1988. El Arte Rupestre del Este de Catamarca. Las Pictografías de la Candelaria. Dpto. Ancasti, Provincia de Catamarca. Editorial Universitaria. Facultad de Humanidades. Universidad Nacional de Catamarca.

Serrano, A.

1968. El Precerámico en la República Argentina y Países Vecinos. Córdoba: Instituto de Antropología de Córdoba, Universidad Nacional de Córdoba.

Severi, C.

2010. El Sendero y la Voz. Una antropología de la Memoria. Editorial SB, Buenos Aires.

Troncoso, A.

2007. Arte rupestre y microespacios en el Valle de Putaendo, Chile: entre la movilidad, la visibilidad y el sentido. En Procesos Sociales Prehispánicos en el sur Andino. La vivienda, la comunidad y el territorio, compilado por A. Nielsen y otros, pp. 393-411. Brujas, Córdoba. 2008. Arquitectura imaginaria y ritualidad del movimiento: arte rupestre y espacio en el cerro Paidahuen, Chile central. En Sed non Satiata II. Acercamientos Sociales en la Arqueología Latinoamericana, compilado por F. Acuto y A. Zarankin, pp. 279-302. Editorial Brujas, Córdoba.

Turner, V. 1999 [1967]. La selva de símbolos. Aspectos del ritual ndembu. $4^{\text {a }}$ edición en español. Siglo XXI, Madrid.

Van Gennep, A.

2008 [1909]. Los ritos de paso. Alianza Editorial, Madrid. 